\title{
Centaur Test Bed (CTB) for Cryogenic Fluid Management
}

Steven Sakla, Bernard Kutter, and John Wall

Lockheed Martin Space Systems Company, Denver, Colorado 


\section{NASA STI Program . . . in Profile}

Since its founding, NASA has been dedicated to the advancement of aeronautics and space science. The NASA Scientific and Technical Information (STI) program plays a key part in helping NASA maintain this important role.

The NASA STI Program operates under the auspices of the Agency Chief Information Officer. It collects, organizes, provides for archiving, and disseminates NASA's STI. The NASA STI program provides access to the NASA Aeronautics and Space Database and its public interface, the NASA Technical Reports Server, thus providing one of the largest collections of aeronautical and space science STI in the world. Results are published in both non-NASA channels and by NASA in the NASA STI Report Series, which includes the following report types:

- TECHNICAL PUBLICATION. Reports of completed research or a major significant phase of research that present the results of NASA programs and include extensive data or theoretical analysis. Includes compilations of significant scientific and technical data and information deemed to be of continuing reference value. NASA counterpart of peer-reviewed formal professional papers but has less stringent limitations on manuscript length and extent of graphic presentations.

- TECHNICAL MEMORANDUM. Scientific and technical findings that are preliminary or of specialized interest, e.g., quick release reports, working papers, and bibliographies that contain minimal annotation. Does not contain extensive analysis.

- CONTRACTOR REPORT. Scientific and technical findings by NASA-sponsored contractors and grantees.
- CONFERENCE PUBLICATION. Collected papers from scientific and technical conferences, symposia, seminars, or other meetings sponsored or cosponsored by NASA.

- SPECIAL PUBLICATION. Scientific, technical, or historical information from NASA programs, projects, and missions, often concerned with subjects having substantial public interest.

- TECHNICAL TRANSLATION. Englishlanguage translations of foreign scientific and technical material pertinent to NASA's mission.

Specialized services also include creating custom thesauri, building customized databases, organizing and publishing research results.

For more information about the NASA STI program, see the following:

- Access the NASA STI program home page at http://www.sti.nasa.gov

- E-mail your question via the Internet to help@sti.nasa.gov

- Fax your question to the NASA STI Help Desk at 301-621-0134

- Telephone the NASA STI Help Desk at 301-621-0390

- Write to:

NASA STI Help Desk

NASA Center for AeroSpace Information 7121 Standard Drive Hanover, MD 21076-1320 


\section{Centaur Test Bed (CTB) for Cryogenic Fluid Management}

Steven Sakla, Bernard Kutter, and John Wall

Lockheed Martin Space Systems Company, Denver, Colorado

Prepared for the

42nd Joint Propulsion Conference and Exhibit cosponsored by the AIAA, ASME, SAE, and ASEE

Sacramento, California, July 9-12, 2006

Prepared under Purchase Order NNC05QA89P

National Aeronautics and

Space Administration

Glenn Research Center

Cleveland, Ohio 44135 
Trade names and trademarks are used in this report for identification only. Their usage does not constitute an official endorsement, either expressed or implied, by the National Aeronautics and Space Administration.

Level of Review: This material has been technically reviewed by expert reviewer(s).

Available from

NASA Center for Aerospace Information 7121 Standard Drive

Hanover, MD 21076-1320
National Technical Information Service 5285 Port Royal Road Springfield, VA 22161 


\title{
Centaur Test Bed (CTB) for Cryogenic Fluid Management
}

\author{
Steven Sakla, Bernard Kutter, and John Wall \\ Lockheed Martin Space Systems Company \\ Denver, Colorado 80201
}

\begin{abstract}
Future missions such as NASA's space exploration vision and DOD satellite servicing will require significant increases in the understanding and knowledge of space based cryogenic fluid management (CFM), including the transfer and storage of cryogenic fluids. Existing CFM capabilities are based on flight of upper stage cryogenic vehicles, scientific dewars, a few dedicated flight demonstrations and ground testing. This current capability is inadequate to support development of the CEV cryogenic propulsion system, other aspects of robust space exploration or the refueling of satellite cryo propulsion systems with reasonable risk. In addition, these technologies can provide significant performance increases for missions beyond low-earth orbit to enable manned missions to the Moon and beyond.

The Centaur upper-stage vehicle can provide a low cost test platform for performing numerous flight demonstrations of the full breadth of required CFM technologies to support CEV development. These flight demonstrations can be performed as secondary mission objectives using excess $\mathrm{LH}_{2}$ and/or $\mathrm{LO}_{2}$ from the main vehicle propellant tanks following primary spacecraft separation at minimal cost and risk.
\end{abstract}

\section{Acronyms}

$\begin{array}{ll}\text { CEV } & \text { Crew Exploration Vehicle } \\ \text { CLV } & \text { Crew Launch Vehicle } \\ \text { CTB } & \text { Centaur Test Bed } \\ \text { DOD } & \text { Department of Defense } \\ \text { EDS } & \text { Earth Departure Stage } \\ \text { g } & \text { Earth's Gravity } \\ \text { INU } & \text { Inertial Navigation Unit } \\ \text { LAD } & \text { Liquid Acquisition Device } \\ \text { LEO } & \text { Low Earth Orbit } \\ \text { LH } & \text { Liquid Hydrogent } \\ \text { LO }_{2} & \text { Liquid Oxygen } \\ \text { LOI } & \text { Lunar Orbit Insertion } \\ \text { LSAM } & \text { Lunar Surface Access Module } \\ \mathrm{N}_{2} \mathrm{H}_{4} & \text { Hydrazine } \\ \text { PMD } & \text { Propellant Management Device } \\ \text { RCS } & \text { Reaction Control System } \\ \text { SM } & \text { Service Module } \\ \text { TEI } & \text { Trans Earth Injection }\end{array}$

\section{Introduction}

The high performance, reliable Centaur upper-stage vehicle has a long history of performing flight experiments using excess $\mathrm{LO}_{2}$ or $\mathrm{LH}_{2}$ propellant following completion of primary mission objectives (i.e., spacecraft separation). Most Atlas/Centaur missions have excess propellants, ranging from hundreds to thousands of pounds. This excess $\mathrm{LH}_{2}$ or $\mathrm{LO}_{2}$ propellant can provide large quantities of working fluid for CFM demonstrations. This ability to utilize excess propellant rather than providing dedicated 
performance and cryo dewars enables the Centaur to enact cost effective CFM demonstrations with minimal performance impact and low risk to the primary mission. Implementing the Centaur Test Bed (CTB) on the $\mathrm{LO}_{2}$ aft bulkhead separates the cryo demonstration from the primary payload, easing integration. Some examples of recent Centaur based CFM experiments include pulsed chilldown of the feedlines and main engine, low-g propellant settling and $\mathrm{LO}_{2}$ unbalanced venting. Space exploration initiatives will require new capabilities such as long-term cryogenic storage, propellant acquisition and propellant transfer. The use of the CTB can provide the overall best value for performing in-flight experiments in a low-g environment through "rideshare" opportunities by flying these experiments as secondary payloads to significantly advance CFM technology in support of NASA's space exploration initiatives and satellite refueling missions.

\section{CTB Overview}

The CTB concept is composed of the addition of a "receiver" bottle to the Centaur aft bulkhead, a control panel, and plumbing connecting the bottle to the $\mathrm{LO}_{2}$ or $\mathrm{LH}_{2}$ tanks, (fig. 1). This receiver bottle would enable the transfer of $\mathrm{LO}_{2}$ or $\mathrm{LH}_{2}$ from the Centaur main tanks to the CTB, storage of the cryogens on the CTB, transfer of the cryogens back to the Centaur tanks and the venting of the cryogens overboard.

The Centaur cryogens are accessed via the installation of tubing connected to the $\mathrm{LO}_{2}$ or $\mathrm{LH}_{2}$ feedlines. During the nominal mission, a redundant valve isolates the CTB system from the Centaur's propulsion hardware to minimize risk to the primary mission. Following spacecraft separation these valves are opened allowing the controlled transfer of cryogens to the CTB.

The Centaur aft bulkhead contains sufficient space for the installation of a CTB as large as 48 by 30 by $30 \mathrm{in}$. A CTB of this scale is large enough to adequately test most CFM requirements. Existing flight hardware of similar size is already integrated on Centaur.

For missions requiring the demonstration of alternative cryogens, e.g., $\mathrm{LCH}_{4}$, another bottle containing the cryogen could be added to the Centaur aft bulkhead. This additional bottle would be connected to the $\mathrm{CTB}$, providing the source cryogen for orbital demonstration.

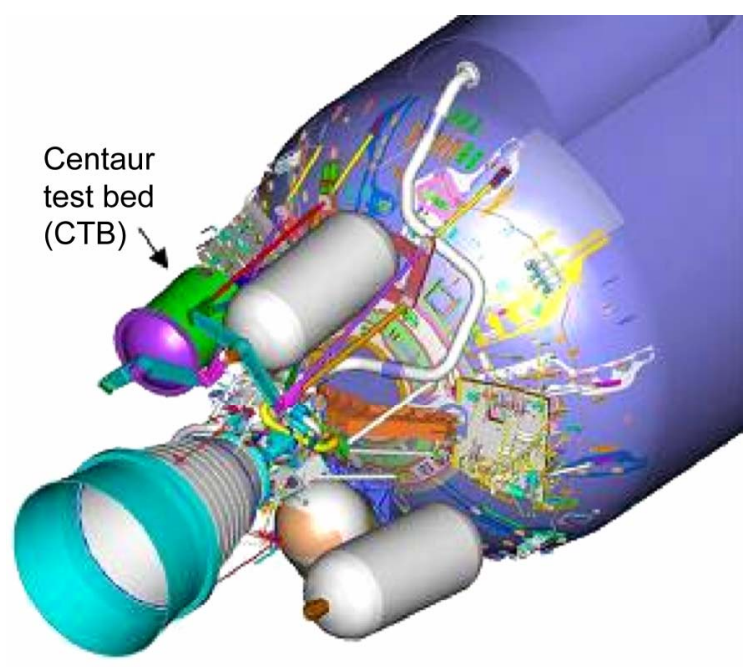

Figure 1.-The Centaur Test Bed (CTB) concept offers affordable, flexible CFM demonstration satisfying NASA's near-term CFM requirements. 


\section{CTB Benefits}

The CTB is designed to advance all manner of CFM and cryo transfer technologies under zero-G or definable low acceleration. The technologies that CTB can address include:

- Liquid acquisition and propellant management devices

- Mass gauging

- Cryo transfer efficiency

- Fluid stratification and mixing

- Liquid inflow geysering

- System chilldown

- No vent fill

- Transfer coupling control

- System operation

- Long duration storage technologies

- Pressure control

- Active and passive cooling

\section{Large Scale Demonstrations}

The Centaur team has taken advantage of the unparalleled recent cryo flight experience, (fig. 2), including 100 flights since 1990, to refine Lockheed Martin's CFM understanding and the operation of cryogenic systems. This learning has benefited from the numerous unique mission profiles and augmented by dozens of post mission demonstrations. A partial list of the broad range of Centaur flight CFM experience is shown in table 1. These demonstrations are used to evolve Atlas and Centaur's capability in a pragmatic, minimal risk manner.

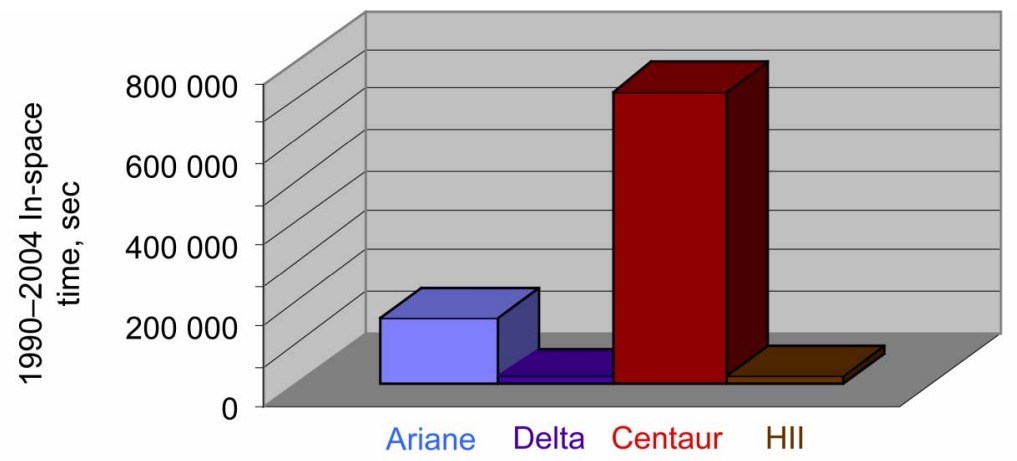

Figure 2.-Centaur's long history, high-flight rate, and long-duration-mission capability results in unparalleled cryo-fluid management experience. 
TABLE 1.-CENTAUR HAS CONDUCTED NUMEROUS FLIGHT DEMONSTRATIONS OF CFM RELEVANT TO CRYO TRANSFER

\begin{tabular}{|l|l|}
\hline Liquid control $\left(10^{-5}\right.$ to 6 G's $)$ & Long coast impact $(17 \mathrm{hr})$. \\
\hline Feed system warming and chilldown & Pressurization sequencing \\
\hline Propellant pullthrough & Slosh characterization \\
\hline Ullage/wall thermal effect & Vent sequencing \\
\hline Ullage and liquid stratification & Pressure collapse \\
\hline Propellant utilization & Bubbler versus ullage pres. \\
\hline Mass gauging & Unbalanced venting \\
\hline
\end{tabular}

For CFM technologies requiring large scale demonstration, the Centaur itself provides an ideal platform. CFM technologies, such as circulation, spray bars, insulation systems, and liquid acquisition, (fig. 3), can be integrated directly to the Centaur and demonstrated as a ride share, or on dedicated mission. System interaction in particular will benefit from the large scale the Centaur has to offer.

\section{System operation}

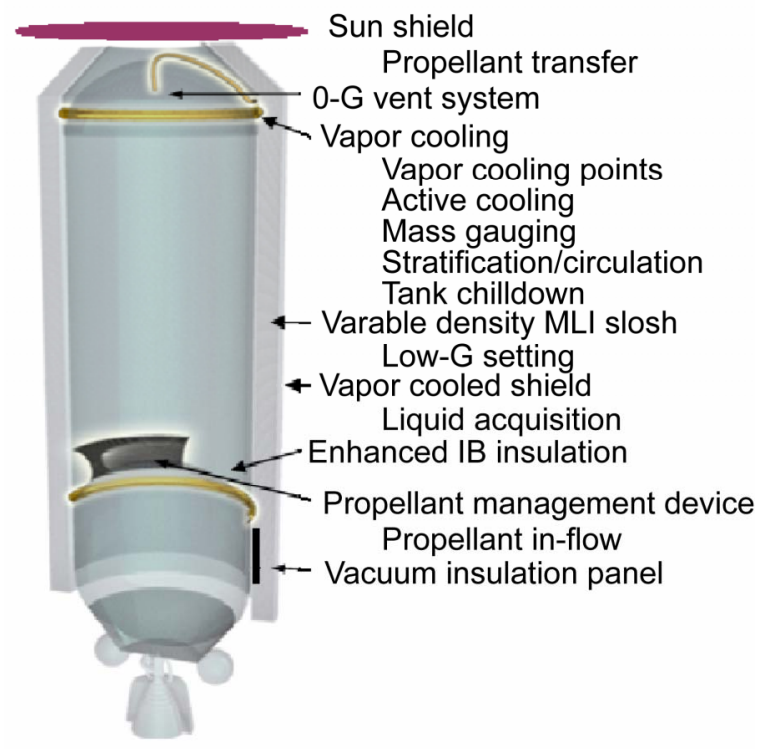

Figure 3.-Centaur can provide the platform for large scale CFM demonstrations. 


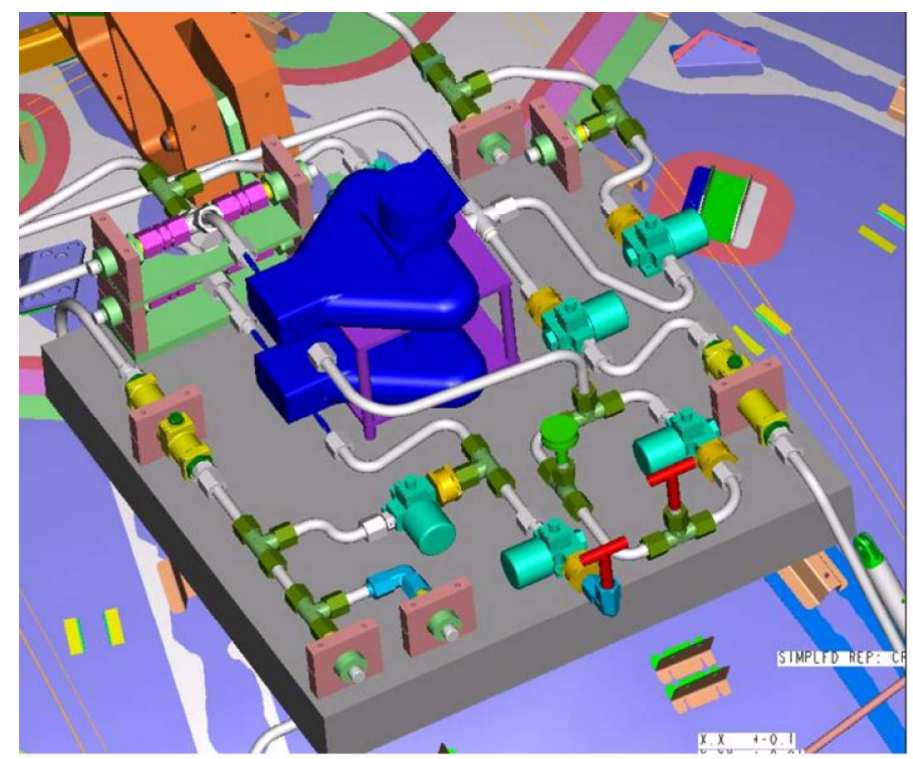

Figure 4.-CTB control panel.

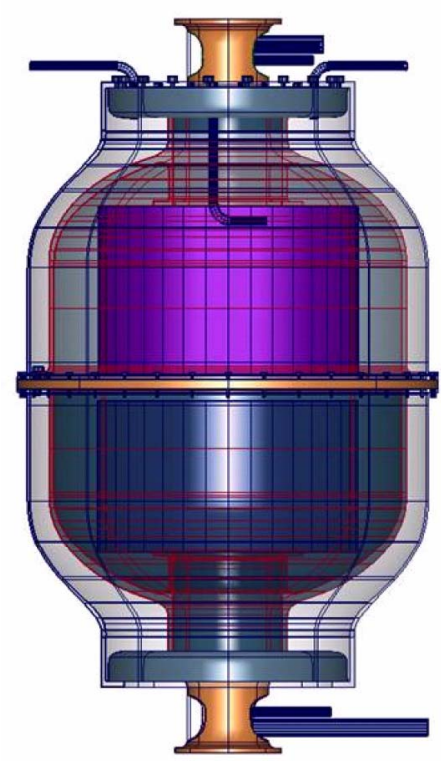

Figure 5.-CTB receiver bottle.

\section{CTB Design Overview}

The CTB's primary components consist of a control panel as shown in figure 4 and a receiver bottle shown in figure 5 . The control panel contains all of the necessary solenoid valves, pyro isolation valves and instrumentation to support the in-flight experiment. The CTB control panel module and receiver bottle would be qualified and acceptance tested as a complete system prior to installation on the vehicle. The receiver bottle consists of an inner and outer shroud. The outer shroud is used as a vapor-cooled shield to minimize boil-off losses during cryo transfer process and is also used for initial chilldown the receiver bottle prior to cryo fluid transfer.

\section{Leveraging Existing Designs}

The design concept of the CTB leverages off of existing Centaur hardware and design practices in an effort to minimize design and mission risk. The CTB control panel is a modular system containing instrumentation and valving to control the flight experiment. This control panel is similar in design to the existing pneumatics panel which has been in flight service for several years. The receiver bottle is similar in size and weight to existing GHe storage and $\mathrm{N}_{2} \mathrm{H}_{4}$ storage bottles currently in use on the Centaur. Therefore, the bottle design and support methods for the receiver bottle are within the design, development and flight experience of the Atlas/Centaur program. Use of existing, flight-qualified cryogenic solenoid valves would also be employed in the CTB control architecture.

The recently upgraded Centaur avionics system contains sufficient battery power to support a $>5 \mathrm{hr}$. CTB flight demonstration test following separation of the primary customer's spacecraft. This avionics system also has sufficient switching and control capability to support up to 10 additional solenoid control valves, numerous instrumentation transducers and pyrovalve control switches. 


\section{Conclusion}

The high performance, reliable Centaur upper-stage vehicle has a long history of performing flight experiments. This successful history along with sufficient real-estate and structural margins on the Centaur aft bulkhead can be used to provide a significant technological benefit in the advancement of CFM technologies in a micro-g environment. Furthermore, these in-flight experiments can be performed at a much lower cost than a dedicated spacecraft or mission by using "rideshare" opportunities and flying the CTB as secondary payload. The CTB can provide near-term technology benefits for NASA to advance its space exploration goals to the Moon and beyond. They can also benefit the DOD or perhaps commercial customer's to demonstrate refueling of orbiting satellite's to greatly extend satellite service life or enhance mission objectives. 


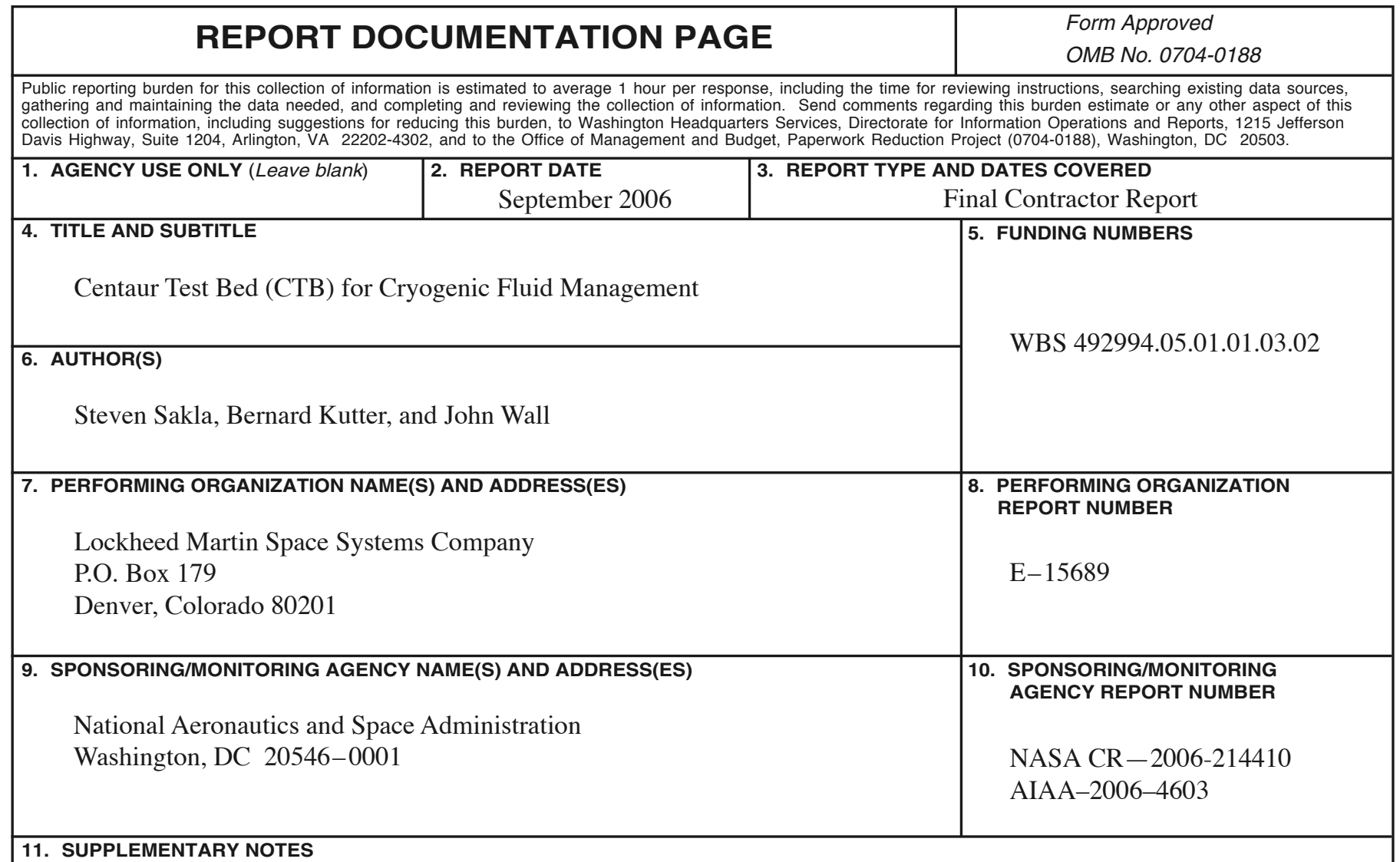

Project manager, David J. Chato, Propellant Systems Branch, NASA Glenn Research Center, organization code RTP, 216-977-7488.

\begin{tabular}{|l|l|}
\hline 12a. DISTRIBUTION/AVAILABILITY STATEMENT & 12b. DISTRIBUTION CODE
\end{tabular}

Unclassified - Unlimited

Subject Category: 34

Available electronically at http://gltrs.grc.nasa.gov

This publication is available from the NASA Center for AeroSpace Information, 301-621-0390.

13. ABSTRACT (Maximum 200 words)

Future missions such as NASA's space exploration vision and DOD satellite servicing will require significant increases in the understanding and knowledge of space based cryogenic fluid management (CFM), including the transfer and storage of cryogenic fluids. Existing CFM capabilities are based on flight of upper stage cryogenic vehicles, scientific dewars, a few dedicated flight demonstrations and ground testing. This current capability is inadequate to support development of the CEV cryogenic propulsion system, other aspects of robust space exploration or the refueling of satellite cryo propulsion systems with reasonable risk. In addition, these technologies can provide significant performance increases for missions beyond low-earth orbit to enable manned missions to the Moon and beyond. The Centaur upper-stage vehicle can provide a low cost test platform for performing numerous flight demonstrations of the full breadth of required CFM technologies to support CEV development. These flight demonstrations can be performed as secondary mission objectives using excess $\mathrm{LH}_{2}$ and/or $\mathrm{LO}_{2}$ from the main vehicle propellant tanks following primary spacecraft separation at minimal cost and risk.

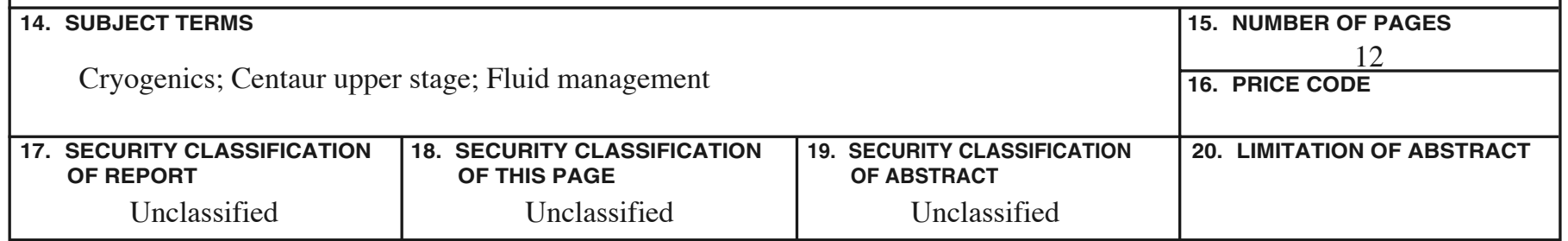

NSN 7540-01-280-5500

Standard Form 298 (Rev. 2-89) 

